\title{
Development of Advance Extraction Methods for the Extraction of Myristicin from Myristica fragrans
}

\author{
Julia Nowak ${ }^{1}$ - Michał Woźniakiewicz ${ }^{1} \cdot$ Marta Gladysz $^{1}$ • \\ Anna Sowa ${ }^{1}$ - Pawel Kościelniak ${ }^{1}$
}

Received: 18 May 2015 / Accepted: 20 August 2015 / Published online: 4 September 2015

(C) The Author(s) 2015. This article is published with open access at Springerlink.com

\begin{abstract}
Myristicin in a psychoactive, hallucinogenic substance and as a constituent of nutmeg and mace (Myristica fragrans nut and its aril, respectively) is widely available for people seeking so-called legal highs of natural origin. In this work, we present three methods for determination of myristicin from plant material. The methods consist of optimized extraction procedures: microwave-assisted extraction, ultrasound-assisted extraction utilizing ultrasound bath or sonotrode and gas chromatography-mass spectrometry (GCMS) analysis method. The methods were validated: repeatability and intermediate were below $10 \%$ and recovery ranged from 97 to $109 \%$. The developed methods were then used for determination of myristicin in commercially available nutmeg and mace samples. The concentration ranged from 0.58 to $12.94 \mu \mathrm{g} \mathrm{mg}^{-1}$, and the highest concentration of myristicin was observed in samples of those producers, which are often recommended by individuals experimenting with nutmeg. The microwave-assisted extraction (MAE) method has been proven to be the most effective one for the extraction of myristicin from plant material, as it also generates deeper changes in sample structure than UAE techniques. The MAE/GC-MS method was successfully used for nutmeg residue analysis, allowing identification of five characteristic violate constituents of nutmeg.
\end{abstract}

Electronic supplementary material The online version of this article (doi:10.1007/s12161-015-0300-x) contains supplementary material, which is available to authorized users.

Michał Woźniakiewicz

michal.wozniakiewicz@uj.edu.pl

1 Laboratory for Forensic Chemistry, Department of Analytical Chemistry, Faculty of Chemistry, Jagiellonian University in Kraków, Ingardena 3, 30-060 Krakow, Poland
Keywords Myristicin · Myristica fragrans $\cdot$ Nutmeg · Microwave-assisted extraction · Ultrasound-assisted extraction - GC-MS

\section{Introduction}

Myristicin is the main psychoactive substance in Myristica fragrans and one of the main constituents of its essential oil. Myristicin content in plant organs varies, depending on both growing and storage condition, and it can amount up to $13 \mathrm{mg}$ per $1 \mathrm{~g}$ in the high-quality M. fragrans nut (nutmeg); it is also abundant in aril of the nut (mace) (Hallström and Thuvander 1997) and its pericarp (Choo et al. 1999). Psychoactive effects usually develop after administration of at least $10 \mathrm{~g}$ of grounded nutmeg and include amphetamine-like effects and hallucinations (Ehrenpreis et al. 2014). For this reason, nutmeg is often abused as so-called legal high by young people looking for economic and easily available alternative to illicit drugs. The abuse of nutmeg may lead to poisonings, as even fatal ones have been reported (Sjöholm et al. 1998; Stein et al. 2001; Carstairs and Cantrell 2011; Ehrenpreis et al. 2014). Therefore, there is a need for an effective method of identification and possibly determination of myristicin, particularly in small sample amounts, which can be left after administration of nutmeg or mace.

The most common method for determination of myristicin in plant material bases on analysis of essential oil obtained by the hydrodistillation (Choo et al. 1999; Kiralan et al. 2012; Pavlović et al. 2012) or the supercritical fluid extraction (SFE) (Machmudah et al. 2006; Piras et al. 2012). Solid-liquid extraction techniques, such as maceration and reflux extraction, as well as ultrasonic-assisted extraction (UAE), i.e. in the ultrasonic bath, were also reported (Choo et al. 1999; Dhalwal et al. 2007; Dawidowicz and Dybowski 2012). A clear 
advantage of hydrodistillation and SFE is lack of organic extraction solvents; however, both techniques require considerable large amount of sample and they are rather time-consuming. On the other hand, the solid-liquid extraction can be adjusted to enable the analysis of small sample amounts, and the time of extraction can be significantly shortened, especially if advanced sample preparation techniques are used. In this work, we present three fast and effective sample preparation methods for determination of myristicin in nutmeg and mace samples, utilizing the UAE techniques: an ultrasonic bath (UAE-B) and an ultrasonic probe or sonotrode (UAE-S), as well as the microwave-assisted extraction (MAE).

The UAE-B technique is a well-known and widely used technique, as it requires only simple equipment, available in most analytical laboratories. UAE-S, however, demands a specialized instrument, in which ultrasound waves are generated by a probe, immersed directly in the extraction mixture. This technique enables rapid extraction with high power ultrasound waves, yet it has a disadvantage of allowing only one sample extraction at the time, and it is performed in open vessels. UAE-S has been successfully applied for extraction of small organic compounds from plant material (Torre et al. 2001; Wu et al. 2001; Adam et al. 2009; Sanz-Landaluze et al. 2010; Jerman Klen and Mozetič Vodopivec 2012), but to the authors' best knowledge, it has not been used for extraction of myristicin before.

The second developed technique, MAE, utilizes the energy of electromagnetic waves to enhance the extraction process. Most of MAE apparatus enable multiple extraction in a single run performed even in temperature over a boiling point of extraction solvent, as it is performed in airtight vessels. This technique is becoming more and more popular in the field of sample preparation (Chan et al. 2011), yet there is no published report on using it for samples of $M$. fragrans.

The aim of this work was to develop, optimize and validate novel, fast and simple sample preparation methods, followed by the gas chromatography-mass spectrometry (GC-MS) method, to provide rapid and plausible method for determination of myristicin in as little as a couple milligrams of nutmeg or mace samples, as well as establish the possibility of trace analysis of nutmeg powder, which may be applied in forensics and toxicology.

\section{Materials and Methods}

\section{Materials}

n-Hexane (MS purity grade), methanol (MS purity grade), myristicin, $\gamma$-octalactone (internal standard, IS), alkane standard solution $\mathrm{C}_{8}-\mathrm{C}_{20}$ and magnesium sulphate were purchased from Sigma-Aldrich (St. Louis, MO, USA). Ultrapure water $(18.2 \mathrm{M} \Omega \cdot \mathrm{cm}, 3 \mathrm{ppb}$ TOC) was generated in our laboratory in a Milli-Q system by Merck-Millipore (Darmstadt, Germany).

Samples of nutmeg and mace were purchased from local and online shops, so that there was at least one sample representing each of six widely known producers. There were six samples of grounded nutmeg (GN1-GN6) collected, together with a sample of whole nutmeg (WN6) and sample of mace (NM6) from the same producer as GN6. All samples were kept in original packaging, tightly closed.

\section{Preparation of Stock and Standard Solutions}

Stock solution myristicin $\left(10 \mathrm{mg} \mathrm{mL}^{-1}\right)$, standard solutions (0.1, 0.2, 0.5, 1.0, 5.0, 10.0, 20.0, 30.0, 50.0, $\left.100.0 \mu \mathrm{g} \mathrm{mL}^{-1}\right)$, stock solution of IS $\left(1 \mathrm{mg} \mathrm{mL}^{-1}\right)$ and a standard IS solution $\left(5.0 \mu \mathrm{g} \mathrm{mL}^{-1}\right)$, used in every experiment, were all prepared in $n$-hexane. All stock solutions were stored in amber glass vials at $+4{ }^{\circ} \mathrm{C}$, whereas standard solutions were kept in room temperature and have been analysed in less than $24 \mathrm{~h}$ since preparation.

\section{Instruments}

An XA 220/X analytical balance equipped with a DJ-02 antistatic ionizer (Radwag, Poland) was used in order to minimize the electrostatic force influence on powdered plant tissue samples and in this way to minimize the weighing error. MAE was carried out in a CEM 5 microwave-assisted sample preparation system (CEM, Matthews, NC, USA) equipped with Xpress $^{\circledR}$ PFA extraction vessels (75 mL capacity). UAE-B was carried out in Sonic 3 ultrasonic Bath of $310 \mathrm{~W}$ (Polsonic, Poland), and UAE-S was performed using the Vibra Cell VC-50 device of $50 \mathrm{~W}$ equipped with a sonotrode (Sonic \& Materials Inc., CT, USA).

The GC-MS system consisting of a 6850 Series II gas chromatograph and a 5975C MSD mass spectrometer (Agilent Technologies, USA) was employed. A HP-5 ms ultra inert capillary column $(30 \mathrm{~m}, 0.25 \mathrm{~mm}$ i.d., $0.25 \mu \mathrm{m}$ film thickness) by Agilent Technologies was used. The oven temperature was set to initial temperature of $70^{\circ} \mathrm{C}$, held for $1 \mathrm{~min}$, then increased to $300{ }^{\circ} \mathrm{C}\left(25^{\circ} \mathrm{C} \mathrm{min}-1\right)$ and held for $3 \mathrm{~min}$ with the total analysis time of $13.2 \mathrm{~min}$. Helium was used as a carrier gas with a flow rate of $1.0 \mathrm{~mL} \mathrm{~min}^{-1}$. Injection of $1 \mu \mathrm{L}$ was performed at $290{ }^{\circ} \mathrm{C}$ with 1:4 split for qualitative analysis and, respectively, in splitless mode for trace analysis. The MS transfer line temperature was set up to $290{ }^{\circ} \mathrm{C}$, while the ion source temperature was $230{ }^{\circ} \mathrm{C}$. The electron impact ionization energy of $70 \mathrm{eV}$ was used throughout. The mass range for the MS detector in scan mode was from 45 to $400 \mathrm{~m} / z$. For the SIM mode, monitored ions included $192 \mathrm{~m} / \mathrm{z}$ for myristicin and $85 \mathrm{~m} / \mathrm{z}$ for IS. Qualitative analysis was completed in the SIM mode while analytes identification was performed in the scan mode. For mass spectra identification, NIST 11 (The 
NIST Mass Spectra Search Program, version 2.0 g, 2011) database was used.

\section{Sample Preparation}

\section{Sample Pre-treatment}

For every type of tested extraction technique, 4 to $8 \mathrm{mg}$ of sample was used, depending on concentration of myristicin assessed in preliminary experiments. Samples of whole nutmeg were grounded directly before weighing, and samples of grounded nutmeg and mace were analysed without any additional pre-treatment. For quantitative analysis, samples were prepared in triplicate.

For the trace analysis, several milligrams of GN3 and GN4 were placed on plastic foil, evenly distributed and then removed, so that only a trace amount of powder was left due to electrostatics. Then, 5-, 10-, 15- and 20-cm segments of foil were wiped in a single straight move with sterile cotton swabs pre-wetted in ultrapure water. The segments were $0.3-0.4 \mathrm{~cm}$ wide, which was determined by the shape of the swabs. Whole swabs were extracted using the optimized MAE procedure. The samples were prepared in duplicate.

\section{Optimisation of Sample Preparation Method}

During development of sample preparation method, the following factors were taken into consideration: type of extraction reagent - polar or nonpolar solvents; amount of sample and volume of solvent; choice of IS; and two extraction parameters, time and temperature. Due to the different characteristic of investigated extraction techniques, a common procedure of optimisation of extraction parameters could not be executed and every method had to be optimized independently. The criterion used for optimisation was the highest amount of myristicin after extraction, defined as peak area of the extracted ion chromatogram at $\mathrm{m} / \mathrm{z} 192$, for $1 \mathrm{mg}$ of the sample.

The MAE procedure was evaluated in time range from 10 to $30 \mathrm{~min}$, with 10-min step, and on two temperature levels: 50 and $70^{\circ} \mathrm{C}$, at $800 \mathrm{~W}$ (default power for extraction procedures, as application of higher power, e.g. $1600 \mathrm{~W}$ as it is possible in case of MARS 5, disturbs controlling of temperature, especially when low solvent volumes are used). Temperatureconstant heating was chosen over power-constant one to avoid overheating, which could result in analyte degradation or depressurization of extraction vessels and uncontrolled evaporation of extraction solvent. Moreover, an important requirement for MAE is that the polar liquid should be present in the extraction system, due to the fact that only substances with non-zero dipole moment can absorb microwaves and then distribute energy thorough the extraction mixture.

UAE-S procedure was evaluated in time duration of $0.5,1,2$, 3,4 and 5. UAE-S procedure cannot be held in thermostatic conditions, as the sonotrode produces excessive heat while operating. For this reason, extraction was always started from the room temperature and then the temperature of extraction mixture was verified directly after the extraction process. The UAE-S apparatus can operate at 25 and $50 \mathrm{~W}$; however, preliminary experiments indicated that $25 \mathrm{~W}$ is ineffective.

In case of UAE-B, the authors aimed to reproduce conditions described in literature (Dawidowicz and Dybowski 2012). As eventually different solvent was used, temperature of extraction was optimized. The power of ultrasound bath $(310 \mathrm{~W})$ is fixed by a manufacturer.

\section{Method Validation}

The linearity, limit of detection (LOD) and limit of quantification (LOQ) were common for all tested extraction methods, while recovery and precision were evaluated separately. The linearity was tested by analysing a set of standard solutions, and LOD and LOQ were calculated as three and ten times the standard deviation of the response for the lowest concentration standard solution to the slope of the calibration curve.

As there is no myristicin-free nutmeg, it is impossible to obtain blank samples. Thus for the precision study, nutmeg samples were tested on three concentration levels: low (4.7 $\left.\mu \mathrm{g} \mathrm{mg}^{-1}\right)$, mid $\left(6.5 \mu \mathrm{g} \mathrm{mg}^{-1}\right)$ and high $\left(9.2 \mu \mathrm{g} \mathrm{mg}^{-1}\right)$, by analysing three kinds of nutmeg samples: one of the lowest, one of the highest myristicin concentration and finally one from the middle of the range of myristicin concentration. While testing of recovery, a chosen testing nutmeg sample, containing $2.8 \mu \mathrm{g} \mathrm{mg}^{-1}$ myristicin, was spiked with an equivalent of about 25,50 and $75 \%$ of myristicin amount and then it was analysed in three replicates. The intra- and interday precision were evaluated as repeatability and intermediate precision, respectively, and they were calculated by one-way ANOVA from results obtained in 3 days, with five replicates a day. The threshold limit for precision and recovery study was set to $10 \%$, while the linearity demanded $R^{2}>0.995$.

\section{Results and Discussion}

\section{Optimized Extraction Procedures}

\section{Extraction Solvent}

According to the mentioned literature, it may be stated that the most commonly used extraction solvent for myristicin isolation is methanol. In this work, $n$-hexane was also tested, as it was assumed that the use of nonpolar solvent should provide better extraction efficiency and higher selectivity. Indeed, comparison application of these solvents revealed that $n$-hexane is a better choice when aiming for more selective extraction of allylbenzenes (Table 1). 
Table 1 Identification of peaks in GC-MS run after $n$-hexane and methanol MAE extraction $\left(70^{\circ} \mathrm{C}\right.$, $10 \mathrm{~min}$ ) of equal amounts of nutmeg sample. The compounds were identified using NIST 11 database

\begin{tabular}{lllll}
\hline Retention time (min) & LRI $^{\mathrm{a}}$ & Compound & \multicolumn{2}{l}{ Relative abundance after MAE extraction ${ }^{\mathrm{b}}(\%)$} \\
\cline { 5 - 5 } & & & $n$-Hexane & Methanol \\
\hline 6.36 & 1467 & Eugenol & 14 & 7 \\
6.57 & 1504 & Methyleugenol & 4 & 2 \\
6.70 & 1540 & Myristicin & 100 & 42 \\
6.85 & 1562 & Elemicin & 5 & 4 \\
7.11 & 1618 & Methoxyeugenol & 22 & 27 \\
7.62 & 1726 & Myristic acid methyl ester & Not detected & 56 \\
7.77 & 1757 & Myristic acid & 7 & 4 \\
$11.30-11.60$ & & Sterols & $\leq 21$ & $\leq 8$ \\
\hline
\end{tabular}

${ }^{\text {a }}$ Linear retention indices (LRI) determined experimentally for HP-5 ms GC column, using $n$-alkanes mixture

${ }^{\mathrm{b}}$ Expressed as percentage of abundance of myristicin peak after extraction in $n$-hexane

\section{Sample and Solvent Amount, Choice of IS}

The developed methods should be able to operate with low sample amounts, but in such case, the weighting of the sample introduce a significant error. It was assumed that the lowest acceptable uncertainty of sample weighting is $5 \%$ and for XA $220 / \mathrm{X}$ analytical balance, such accuracy is achieved for about $3.7 \mathrm{mg}$ of sample. For this reason, the chosen sample amount used in the procedure was $4.0 \pm 0.1 \mathrm{mg}$.

As it was verified in the preliminary experiments, at least $7 \mathrm{~mL}$ of solvent is needed for even heating during the MAE procedure. Therefore, $5 \mathrm{~mL}$ of $n$-hexane with IS and $2 \mathrm{~mL}$ of ultrapure water were used to form a two-phase extraction mixture. It was experimentally checked that the quantity of myristicin extracted to water phase was negligible. For ultrasound-assisted extraction procedures, only $5 \mathrm{~mL}$ of $n$ hexane with IS were found to be sufficient. Such approach limits organic solvent consumption and disposal production; thus, it favours green chemistry principals.

Concentration of myristicin in the extracts fitted well in the calibration curve for most of the analysed nutmegs. For two nutmegs with the lowest myristicin content, $8.0 \pm 0.1 \mathrm{mg}$ of sample was needed in order to assure that the myristicin concentration in extract will not fall below linearity range.

As unfortunately no deutered standard of myristicin was available in economically reasonable scale, non-deutered substance had to be considered. The choice of IS was restricted by the properties of MAE extraction mixture. A group of natural volatile aroma substances, absent in $M$. fragrans products, characterized by high $\log P$ values, was tested, including phenylethyl acetate, benzyl isobutyrate, methyl cinnamate and $\gamma$-octalactone. But only $\gamma$-octalactone concentration in $n$-hexane was not changed after MAE with water addition, and later, it was also found to be stable in all optimized extraction conditions.

\section{Method Optimization}

For MAE, the best results were obtained for 20 min extraction in $70^{\circ} \mathrm{C}$. Longer extraction process resulted in loss of analyte, probably due to its decomposition (see Fig. 1). Higher temperature of the process resulted in substantially higher extraction efficiency. In case of 5-min-long extraction, significant concentration error may be caused by uneven heat distribution
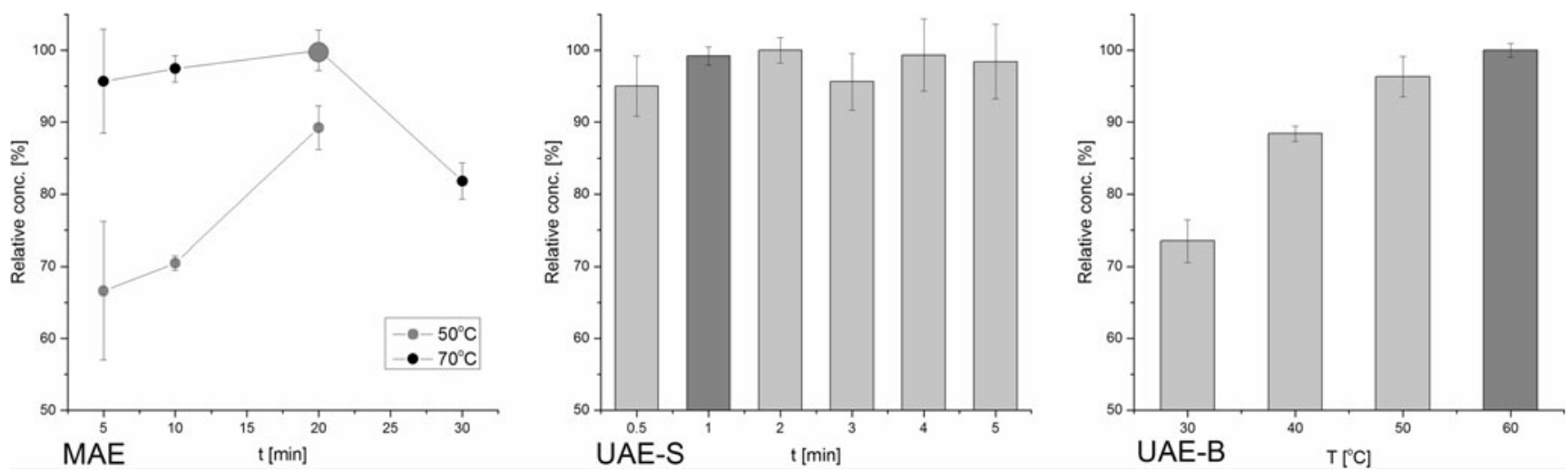

Fig. 1 Relative concentration of myristicin during extraction method optimization for MAE, UAE-S and UAE-B $(n=5)$. The optimal conditions were highlighted 
Table 2 Values of validation parameters for the developed extraction methods

\begin{tabular}{|c|c|c|c|c|c|c|c|c|c|}
\hline & \multicolumn{3}{|c|}{ Repeatability (\%) } & \multicolumn{3}{|c|}{ Intermediate precision $(\%)$} & \multicolumn{3}{|c|}{ Recovery (\%) } \\
\hline & \multicolumn{3}{|c|}{ Conc. level } & \multicolumn{3}{|c|}{ Conc. level } & \multicolumn{3}{|c|}{ Standard addition } \\
\hline & Low & Mid & High & Low & Mid & High & $+25 \%$ & $+50 \%$ & $+75 \%$ \\
\hline MAE & 4.9 & 5.9 & 3.7 & 9.7 & 7.9 & 8.3 & 97 & 104 & 102 \\
\hline UAE-S & 5.2 & 7.4 & 5.9 & 9.7 & 7.3 & 8.0 & 103 & 105 & 109 \\
\hline UAE-B & 4.3 & 7.2 & 4.3 & 7.4 & 7.7 & 8.3 & 105 & 107 & 107 \\
\hline
\end{tabular}

in such short time. For UAE-S, the maximum concentration of myristicin was obtained after only $1 \mathrm{~min}$ of extraction. The average temperature of extraction mixture did not exceed $40{ }^{\circ} \mathrm{C}$ in any case, and therefore, boiling of $n$-hexane was not observed; however, higher concentration error was observed for longer extraction times, possibly due to local overheating of the solvent, caused by cavitation. Lastly, the highest myristicin concentration was obtained after UAE-B in $60{ }^{\circ} \mathrm{C}$. Higher temperature could not be tested, as the extraction vessels were not designed to operate at elevated pressure caused by boiling $n$-hexane.

The completeness of extraction was also evaluated. The samples extracted in optimal conditions were subjected to subsequent extraction process with fresh extracting solvent. No trace of myristicin was found in the secondary extracts, and it was stated that the developed extraction methods guarantee maximum extraction efficiency.

Extracts obtained after optimized extraction procedures could be injected into the GC-MS system directly, without diluting, and no purification was needed other than filtration through $0.22 \mu \mathrm{m}$ PTFE syringe filter. One may find this as the superiority of the developed methods over other ones (Dawidowicz and Dybowski 2012), especially in economical and operational dimensions, as any additional SPE cleaning up was not necessary.

\section{Method Validation}

Repeatability, intermediate precision and recovery are listed in Table 2. Repeatability and intermediate precision fits the range of acceptance within $10 \%$ limit. The recovery was good for each extraction method.

The linearity of the methods was between 0.50 and $100 \mu \mathrm{g} \mathrm{mL}^{-1}$ (corresponding to 0.625 and $125 \mu \mathrm{g} \mathrm{mg}^{-1}$ in relation to $4.0 \mathrm{mg}$ sample, tested on seven calibration points). Higher concentration was not tested as it could result in column overloading. The working range of calibration curve was from 0.50 to $20 \mu \mathrm{g} \mathrm{mL}^{-1}$ (from 0.625 to $125 \mu \mathrm{g} \mathrm{mg}^{-1}$, five calibration points), and $R^{2}$ was between 0.998 and 1.000 through entire validation process. Calculated LOD and LOQ values were 0.03 and $0.10 \mu \mathrm{g} \mathrm{mL}^{-1}(0.0375$ and $0.125 \mu \mathrm{g} \mathrm{mg}^{-1}$ ), respectively. It was assumed that such parameters are suitable for analysis of natural samples of nutmeg and mace in amount of $4 \mathrm{mg}$. The robustness of the method was tested in terms of a sample amount at 4,8 and $20 \mathrm{mg}$, without changing the volume of extraction solution. It revealed that these masses are suitable for the myristicin determination in nutmeg; however, higher mass may require addition dilution of the extract before analysis.

\section{Analysis of Myristicin in Commercially Available Spices}

Results of determination of myristicin in commercially available samples are presented in Fig. 2. Myristicin concentration ranged from $0.6 \mu \mathrm{g} \mathrm{mg}^{-1}$ (GN6, UAE-B) to $12.9 \mu \mathrm{g} \mathrm{mg}^{-1}$ (GN4, MAE).

Concentrations of myristicin in mace sample determined by all three developed methods are consistent with each other, and there is no statistically significant difference between UAE-S and UAE-B, as evaluated using Student $t$ test ( $\alpha=$ $95 \%$ ). However, in case of whole nut and previously
Fig. 2 Concentration of myristicin in nutmeg and mace from popular spice producers $(n=$ 3)

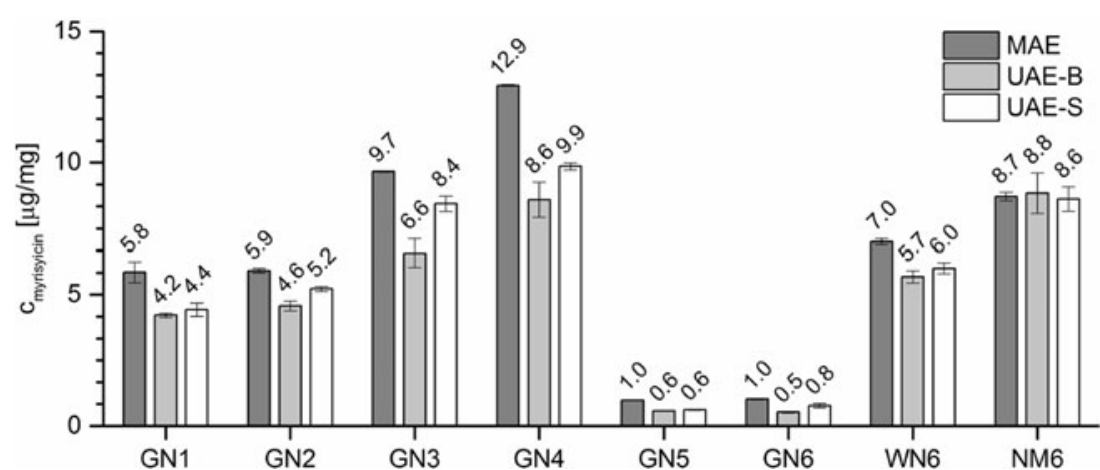



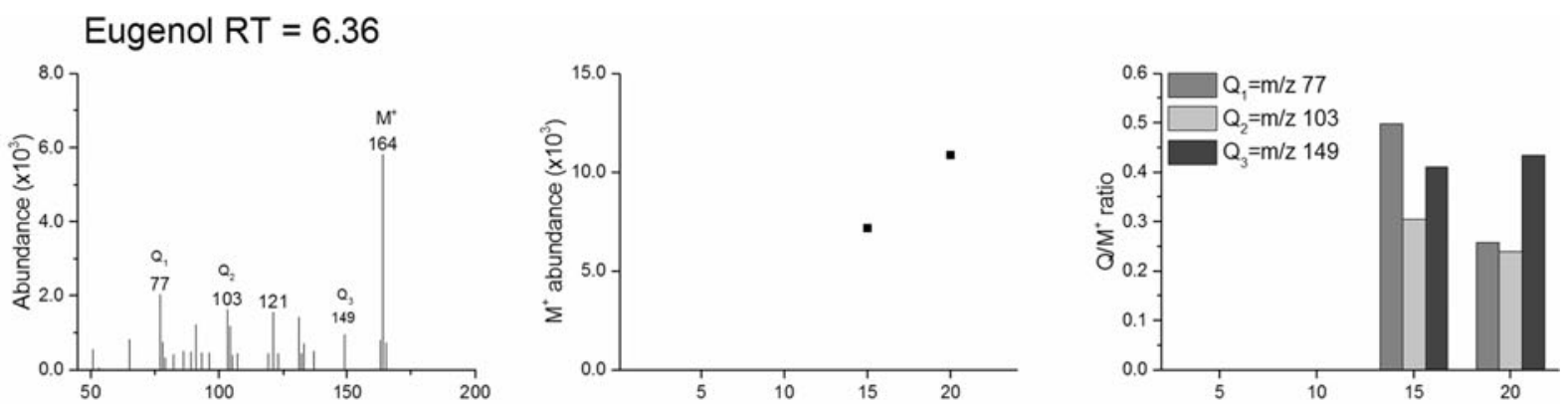

Methyleugenol RT $=6.57$
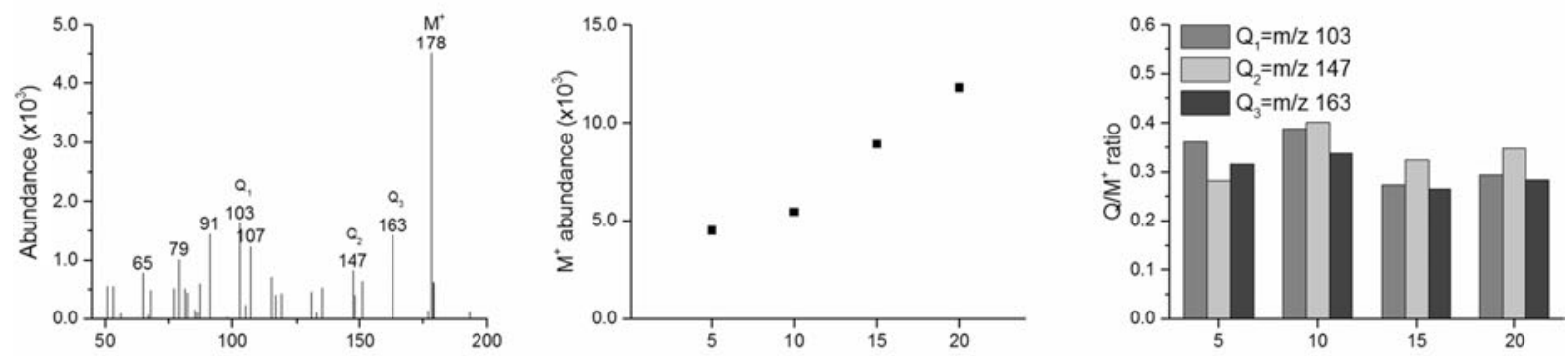

Myristicin RT $=6.70$
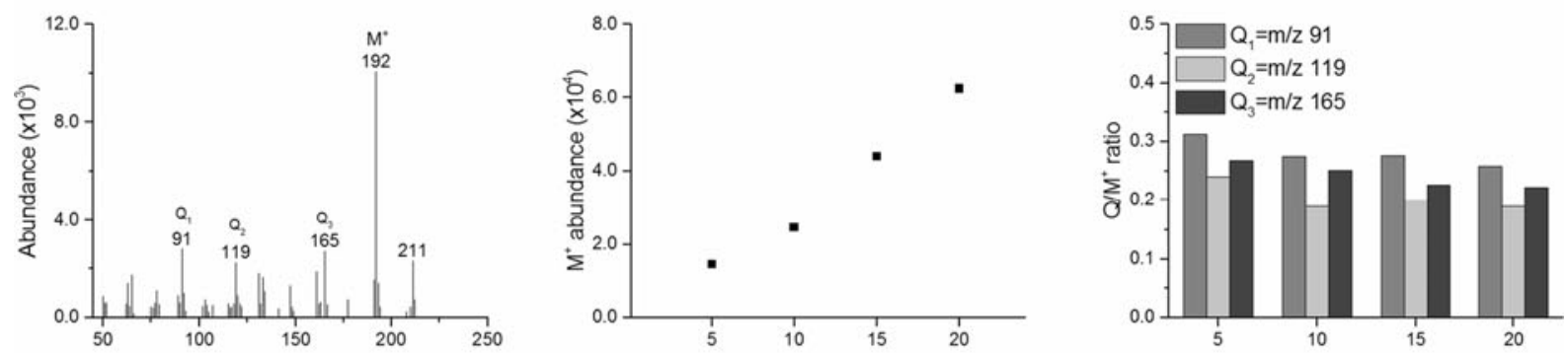

Elemicin RT $=6.85$
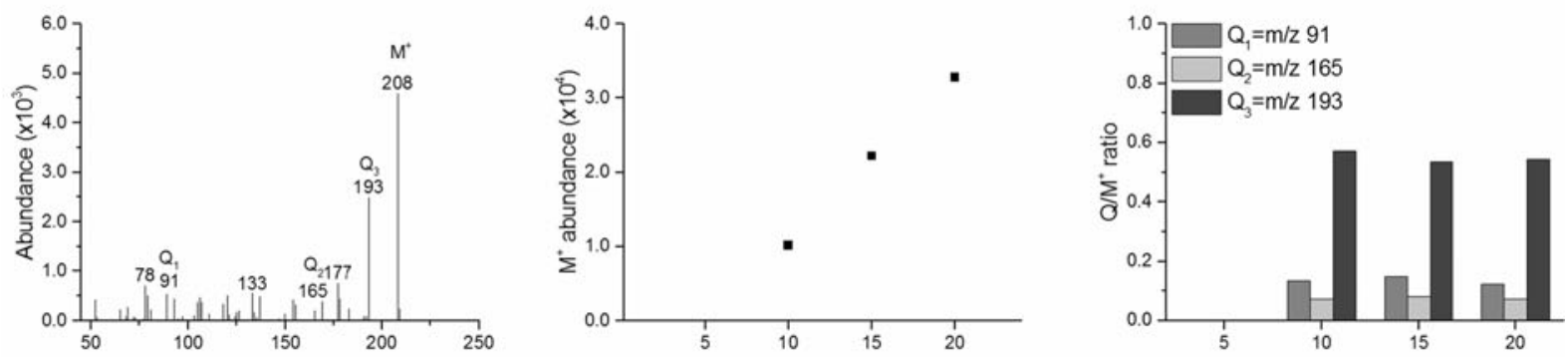

Methoxyeugenol RT $=7.11$
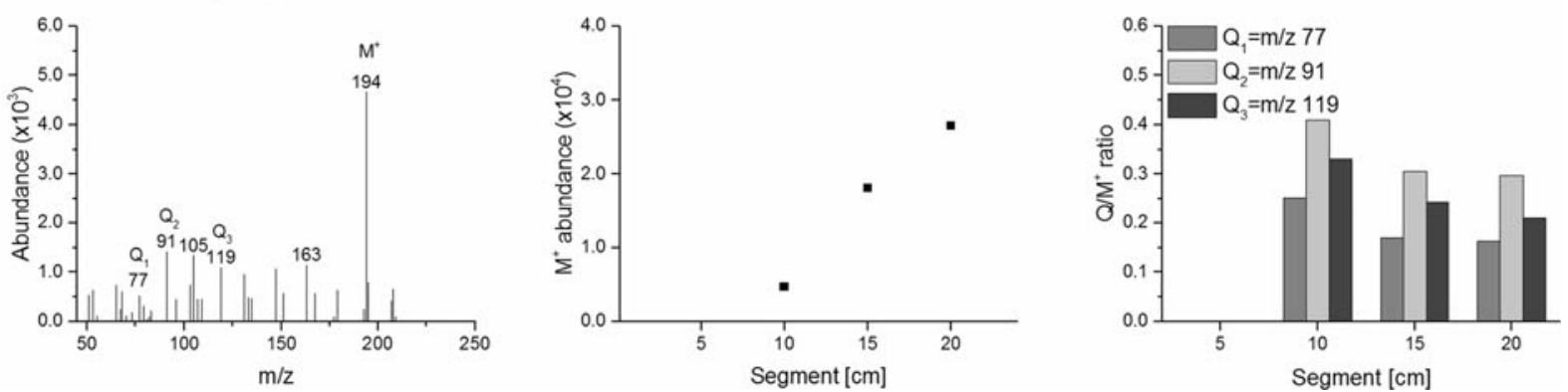
Fig. 3 Analysis of residues of GN4 sample swabbed from plastic foil surface. In columns: mass spectra of identified distinct compound, recorded for the smallest swabbed surface enabling the identification; $\mathrm{M}^{+}$ion abundance in analysed extracts; $\mathrm{Q} / \mathrm{M}^{+}$ratio for three ions

grounded nutmeg, the highest concentration is observed after MAE and the effect is statistically significant ( $\alpha=95 \%$ ). Such relation is not observed in case of mace sample (NM6).

It was theorized that the effect described above results from better extraction efficiency of MAE in case of samples rich in wood constituents, such as cellulose, lignin and others. The hypothesis was verified by analysis of SEM images of grounded nutmeg particles after extraction (see Supplementary Material, section 1). Indeed, investigation of SEM images revealed that MAE caused greater and deeper changes in nutmeg matrix structure than UAE techniques; therefore, it allows better penetration of the extracting solvent and thus more effective myristicin extraction. The effect is not visible for mace, as it consists mostly of natural gum, proteins and fats; hence, its structure is more elastic and disposed to breakdown during extraction.

The results of analysis have given interesting insight into quality of spices available on the market in comparison to preferences of people abusing nutmeg. It is a common sense result that GN contains less myristicin than $\mathrm{WN}$ of the same producer, as it is visible particularly for producer no. 6; however, additionally it can be concluded that producer no. 6 sells spices of generally lower quality than producers no. 1-4. Myristicin concentration found in GN4 is close to maximum reported concentration (Hallström and Thuvander 1997), and on this basis, it can be stated that GN4 is a high-quality spice. Moreover, it was noticed that the results somehow correspond with relations of people abusing nutmeg, published on the Internet (see Supplementary material, section 2), as nutmeg from producers 4, 3 and sometimes 2 are recommended for giving the best psychoactive effects. As psychoactivity of a nutmeg comes from the myristicin content, those relations are in good agreement with the presented results.

\section{Analysis of Trace Amounts of Nutmeg Powder}

For both GN3 and GN4, identification of full MS spectrum, after background subtraction, was possible for: myristicin and methyleugenol-in samples taken from $5 \mathrm{~cm}$ segment; elemicin and methoxyeguenol-in samples taken from $10 \mathrm{~cm}$ segment; and eugenol-in samples taken from $15 \mathrm{~cm}$ segment (Fig. 3). Myristic acid and its methyl ester were not found. The intensity of the most abundant ion (molecular ion, $\mathrm{M}^{+}$, in case of every analysed compound) and intensity ratio of three subsequent ions (qualifier ions, Q) $\mathrm{Q} / \mathrm{M}^{+}$has been assessed. The $\mathrm{Q} / \mathrm{M}^{+}$intensity ratio is stabilizing for longer segments and is consistent with data found in the mass spectra database (Fig. 3). It was therefore proven that the developed method can be used for detecting residues of nutmeg from surfaces such as foil bags, by identifying characteristic violate substances in the extract.

\section{Conclusions}

In this study, three extraction methods utilizing MAE, UAE-S and UAE-B were developed and optimized for determination of myristicin in nutmeg and mace. The procedures are fast and simple and require low volume of organic solvent and only 4 $8 \mathrm{mg}$ of sample, and no additional extract treatment is needed. On the other hand, larger amount of sample can be used if needed, due to wide range of linearity of the GC-MS method, and the developed method can be scaled up to $20 \mathrm{mg}$ of sample. The methods were validated with good results, proving to be suitable for analysis of spices, although UAE-S was characterized by lower precision than other methods. The analysis of natural samples shows that MAE technique is the best suited one for extraction of myristicin from nutmeg and probably other samples rich in cellulose and lignin. Analysis of myristicin concentration in commercially available nutmeg revealed that spices recommended by nutmeg abusers indeed contain the highest extent of myristicin. Moreover, the developed MAE/GC-MS technique was successfully used for identification of residues of grounded nutmeg.

Acknowledgments The authors gratefully acknowledge the Ministry of Science and Higher Education for the financial support (M. Woźniakiewicz, Iuventus Plus 2015-2017, grant no. IP2014 052273). The research was carried out with equipment purchased thanks to the financial support of the European Regional Development Fund within the framework of the Polish Innovation Economy Operational Program (contract no. POIG.02.01.00-12-023/08). The equipment has been used according to the contract policy.

\section{Compliance with Ethical Standards}

Conflict of Interest The authors declare that they have no competing interests.

Ethical Approval This article does not contain any studies with human participants or animals performed by any of the authors.

Informed Consent Informed consent is not applicable for the nature of this study.

Open Access This article is distributed under the terms of the Creative Commons Attribution 4.0 International License (http:// creativecommons.org/licenses/by/4.0/), which permits unrestricted use, distribution, and reproduction in any medium, provided you give appropriate credit to the original author(s) and the source, provide a link to the Creative Commons license, and indicate if changes were made. 


\section{References}

Adam M, Dobiás P, Eisner A, Ventura K (2009) Extraction of antioxidants from plants using ultrasonic methods and their antioxidant capacity. J Sep Sci 32:288-94. doi:10.1002/jssc.200800543

Carstairs SD, Cantrell FL (2011) The spice of life: an analysis of nutmeg exposures in California. Clin Toxicol (Phila) 49:177-80. doi:10. 3109/15563650.2011.561210

Chan C-H, Yusoff R, Ngoh G-C, Kung FW-L (2011) Microwave-assisted extractions of active ingredients from plants. J Chromatogr A 1218: 6213-25. doi:10.1016/j.chroma.2011.07.040

Choo L-C, Wong S-M, Liew K-Y (1999) Essential oil of nutmeg pericarp. J Sci Food Agric 79:1954-1957. doi:10.1002/(SICI)10970010(199910)79:13<1954::AID-JSFA460>3.0.CO;2-I

Dawidowicz AL, Dybowski MP (2012) Determination of myristicin in commonly spices applying SPE/GC. Food Chem Toxicol 50:23627. doi:10.1016/j.fct.2012.04.013

Dhalwal K, Shinde VM, Mahadik KR (2007) Efficient and sensitive method for quantitative determination and validation of umbelliferone, carvone and myristicin in Anethum graveolens and Carum carvi seed. Chromatographia 67:163-167. doi:10.1365/ s10337-007-0473-6

Ehrenpreis JE, Deslauriers C, Lank P, et al (2014) Nutmeg poisonings: a retrospective review of 10 years experience from the Illinois Poison Center, 2001-2011. J Med Toxicol 13-16. doi: 10.1007/s13181013-0379-7

Hallström H, Thuvander A (1997) Toxicological evaluation of myristicin. Nat Toxins 5:186-92. doi:10.1002/nt.3

Jerman Klen T, Mozetič Vodopivec B (2012) Optimisation of olive oil phenol extraction conditions using a high-power probe ultrasonication. Food Chem 134:2481-8. doi:10.1016/j.foodchem. 2012.04.096
Kiralan M, Bayrak A, Abdulaziz OF, Ozbucak T (2012) Essential oil composition and antiradical activity of the oil of Iraq plants. Nat Prod Res 26:132-9. doi:10.1080/14786419.2010. 535149

Machmudah S, Sulaswatty A, Sasaki M et al (2006) Supercritical CO2 extraction of nutmeg oil: experiments and modeling. J Supercrit Fluids 39:30-39. doi:10.1016/j.supflu.2006.01.007

Pavlović I, Petrović S, Radenković M et al (2012) Composition, antimicrobial, antiradical and spasmolytic activity of Ferula heuffelii Griseb. ex Heuffel (Apiaceae) essential oil. Food Chem 130:310 315. doi:10.1016/j.foodchem.2011.07.043

Piras A, Rosa A, Marongiu B et al (2012) Extraction and separation of volatile and fixed oils from seeds of Myristica fragrans by supercritical $\mathrm{CO}_{2}$ : chemical composition and cytotoxic activity on Caco-2 cancer cells. J Food Sci 77:C448-53. doi:10.1111/j.1750-3841.2012.02618.x

Sanz-Landaluze J, Bocanegra-Salazar M, Ortiz-Pérez D, Cámara C (2010) Miniaturisated method for the analysis of polycyclic aromatic hydrocarbons in leaf samples. J Chromatogr A 1217:3567-74. doi:10.1016/j.chroma.2010.03.049

Sjöholm A, Lindberg A, Personne M (1998) Acute nutmeg intoxication. J Intern Med 243:329-31

Stein U, Greyer H, Hentschel H (2001) Nutmeg (myristicin) poisoningreport on a fatal case and a series of cases recorded by a poison information centre. Forensic Sci Int 118:87-90

Torre J, Lorenzo MP, Martínez-Alcázar MP, Barbas C (2001) Simple high-performance liquid chromatography method for alphatocopherol measurement in Rosmarinus officinalis leaves. New data on alpha-tocopherol content. J Chromatogr A 919:305-11. doi:10. 1016/S0021-9673(01)00808-1

Wu J, Lin L, Chau FT (2001) Ultrasound-assisted extraction of ginseng saponins from ginseng roots and cultured ginseng cells. Ultrason Sonochem 8:347-52. doi:10.1016/S1350-4177(01)00066-9 